THE present study was performed to: (a) evaluate the effects of kinin $B_{1}$ (Sar\{D-Phe $\left.{ }^{8}\right\}$-des-Arg-BK; $10 \mathrm{nmol} /$ $\mathrm{kg}$ ) and $\mathrm{B}_{2}$ (bradykinin (BK); $10 \mathrm{nmol} / \mathrm{kg}$ ) receptor agonists on plasma extravasation in selected rat tissues; (b) determine the contribution of a lipopolysaccharide (LPS) $(100 \mu \mathrm{g} / \mathrm{kg})$ to the effects triggered by $B_{1}$ and $B_{2}$ agonists; and (c) characterize the selectivity of $B_{1}\left(\left\{L^{2} u^{8}\right\}\right.$ desArg $\left.-B K ; 10 \mathrm{nmol} / \mathrm{kg}\right)$ and $B_{2}$ (HOE 140; $10 \mathrm{nmol} / \mathrm{kg}$ ) antagonists as inhibitors of this kinin-induced phenomenon. $B_{1}$ and $B_{2}$ agonists were shown to increase plasma extravasation in the duodenum, ileum and also in the urinary bladder of the rat. LPS pretreatment enhanced the plasma extravasation mediated only by the $B_{1}$ agonist in the duodenum, ileum, trachea, main and segmentar bronchi. These effects were prevented by the $B_{1}$. but not the $B_{2}$ antagonist. In normal rats, the $B_{2}$ antagonist inhibited the effect of $B_{2}$ agonist in all the tissues analyzed. However, in LPS-treated rats, the $B_{2}$ antagonist was ineffective in the urinary bladder.

These results indicate that kinins induce plasma extravasation in selected rat tissues through activation of $B_{1}$ and $B_{2}$ receptors, and that LPS selectively enhances the kinin effect on the $B_{1}$ receptor in the duodenum, ileum, trachea and main and segmentar bronchi, and may increase $B_{1}$ receptor expression in these tissues.

Keywords: Kinin receptors, Plasma extravasation, Lipopolysaccharide, Bradykinin, $B_{1}$ expression

\section{Plasma extravasation mediated by lipopolysaccharide-induction of kinin $B 1$ receptors in rat tissues}

\author{
Paulo Roberto Wille ${ }^{1}$, Richard Vitor ${ }^{1}$, \\ Nelson Horacio Gabilan ${ }^{2}$ and Mauro Nicolau ${ }^{1, C A}$
}

${ }^{1}$ Departamento de Ciencias Fisiologicas and ${ }^{2}$ Departamento de Bioquimica, CCB, Universidade Federal de Santa Catarina, Florianopolis, 88040-900, SC, Brazil

\footnotetext{
${ }^{\mathrm{CA}}$ Corresponding Author

Tel: (+55) 483319352

Fax: $(+55) 483319672$

E-mail: mnicolau@mbox1.ufsc.br
}

\section{Introduction}

Kinins are powerful pro-inflammatory peptides that are released from their precursors, the kininogens, by proteolytic cleavage of specific and non-specific kininogenases. ${ }^{1}$ Pharmacological actions of kinins are mediated by $B_{1}$ and $B_{2}$ receptors, the distribution of which has been studied through the use of specific and selective antagonists, ${ }^{2-4}$ and the analysis of protein expression levels. ${ }^{5}$

The kinin $B_{2}$ receptor is constitutively expressed in several different cell types and tissues, and most of the actions of kinins are mediated by this receptor. ${ }^{6-8}$ In contrast, $B_{1}$ receptors are rarely expressed constitutively but, rather, their expression is induced by experimental interventions such as exposure of tissue in vivo or in vitro to bacterial lipopolysaccharides (LPS), interleukin-1 $\beta$ or to ultraviolet irradiation. $^{6}$

Previously, we exploited the effect of LPS on kinin $B_{1}$ receptors to demonstrate the role of these receptors in mediating the vasodilatation in vascular beds of pretreated rats. ${ }^{4}$ These results were observed only when we used the $B_{1}$ agonist, Sar[D-Phe ${ }^{8}$ ]-desArg'-BK, which is resistant to metabolism by angio- tensin-converting enzyme, neutral endopeptidase and aminopeptidases. ${ }^{9}$

In the present study, we investigated the kinin $B_{1}$ receptor-mediated plasma extravasation in two sections of the gastrointestinal tract, in the airways and the urinary bladder, in normal and LPS-treated rats.

\section{Materials and methods}

Evans blue, HOE 140 (icatibant) and formamide were obtained from Sigma (St. Louis, MO, USA). Bradykinin (BK), Sar[D-Phe $\left.{ }^{8}\right]$-des-Arg ${ }^{9}$-BK, and $\left[\mathrm{Leu}^{8}{ }^{8}\right]$ desArg ${ }^{9}$-BK were gifts from D. Regoli (Department of Pharmacology at the Université de Sherbrooke, Canada). The LPS used in this study was from Escherichia coli (serotype 0127:B8) from Difco (Detroit, MI, USA).

Conscious male Wistar rats (200-300 g) were used in these experiments. Protein extravasation was evaluated by measuring tissue content of Evans blue dye, as previously described. ${ }^{10}$ In brief, EB $(20 \mathrm{mg} / \mathrm{kg}$ of a solution containing $25 \mathrm{mg} / \mathrm{ml}$ in $0.9 \% \mathrm{NaCl}$ ) was injected alone or concomitantly with either kinin $\mathrm{B}_{2}$ receptor agonist $\left(\mathrm{BK} ; 10 \mathrm{nmol} / \mathrm{kg}\right.$ ) or the kinin $\mathrm{B}_{1}$ receptor agonist (Sar[D-Phe ${ }^{8}$-des-Arg ${ }^{9}$-BK; $10 \mathrm{nmol} /$ $\mathrm{kg}$ ), in control animals and animals pretreated $24 \mathrm{~h}$ 
earlier with LPS $(100 \mu \mathrm{g} / \mathrm{kg})$. All reagents were administered through the caudal vein. In other experiments, normal and LPS-treated animals were injected with a selective kinin $B_{2}$ receptor antagonist (HOE $140 ; 10 \mathrm{nmol} / \mathrm{kg}$ ), or a selective kinin $B_{1}$ receptor antagonist ([Leu $\left.{ }^{8}\right]$ desArg ${ }^{9}-\mathrm{BK} ; 10 \mathrm{nmol} / \mathrm{kg}$ ), $5 \mathrm{~min}$ before the application of $\mathrm{B}_{1}$ or $\mathrm{B}_{2}$ agonists.

Evans blue was administered and, after $10 \mathrm{~min}$, the animals were decapitated and exsanguinated. The thorax was cut open and the lungs were perfused with $20 \mathrm{ml}$ of $0.9 \% \mathrm{NaCl}(10 \mathrm{ml} / \mathrm{min})$ via a cannula inserted into the pulmonary artery through the right ventricle, to remove the intravascular pulmonary dye. The trachea, main and segmentar bronchi, duodenum, ileum and urinary bladder were dissected and weighed. One-half of each organ was put in formamide while the other half was dried at $50^{\circ} \mathrm{C}$ for $24 \mathrm{~h}$. The concentration of Evans blue dye in the tissues was determined at $620 \mathrm{~nm}$, using an enzymelinked immunosorbent assay plate reader, and was expressed in micrograms per gram of dry weight tissue to avoid error due to edema. ${ }^{10}$

Results are expressed as means (SEM, and data obtained in various groups of animals were compared by analysis of variance followed by a post-boc Neuman-Keuls' test, when necessary. $p<0.05$ was considered significant.

\section{Results}

In the first series of experiments, we studied the effects of a kinin $B_{2}$ receptor agonist (bradykinin) on plasma extravasation in control and LPS-treated rats (Fig. 1). Bradykinin (10 nmol/kg) increased the plasma extravasation in the duodenum, ileum, urinary bladder, trachea, and main and segmentar bronchi by 43, 30, $78,58,27$, and $29 \%$, respectively. The injection of the $\mathrm{B}_{2}$ receptor antagonist HOE $140(10 \mathrm{nmol} / \mathrm{kg})$, before $\mathrm{BK}$, reduced the plasma extravasation to control values in all tissues analyzed in this work. Pretreatment with a LPS $(100 \mu \mathrm{g} / \mathrm{kg})$, for $24 \mathrm{~h}$, resulted in increased plasma extravasation only in the urinary bladder, by $59 \%$. In LPS-treated rats, the injection of $\mathrm{B}_{2}$ agonist produced results similar to those observed with $\mathrm{BK}$ in control animals. Thus, LPS did not exert any significant influence on plasma extravasation induced by $B_{2}$ agonist. Previous injection with the $B_{2}$ antagonist in LPS-treated rats significantly reduced the plasma extravasation induced by BK in the duodenum (31\%), ileum (22\%), trachea (32\%), and main (33\%) and segmentar bronchi (29\%), but not in the urinary bladder. As expected, the $\mathrm{B}_{1}$ antagonist ([Leu $\left.{ }^{8}\right]$ desArg 9 $\mathrm{BK} ; 10 \mathrm{nmol} / \mathrm{kg}$ ) had no effect on plasma extravasation induced by $\mathrm{BK}$ in LPS-treated rats.

In the second series of experiments, we studied the effects of a selective $B_{1}$ agonist (Sar[D-Phe ${ }^{8}$ ]-des-Arg ${ }^{9}$ $\mathrm{BK} ; 10 \mathrm{nmol} / \mathrm{kg}$ ) on plasma extravasation in control and LPS-treated rats (Fig. 2). This $B_{1}$ agonist increased the plasma extravasation in the duodenum (33\%), ileum (35\%), and trachea (38\%). The injection of a selective $B_{1}$ antagonist ([Leu $\left.{ }^{8}\right]$ desArg ${ }^{9}-\mathrm{BK}$ ), before the administration of $B_{1}$ agonist, did not prevent the plasma extravasation in the duodenum, ileum and trachea induced by $B_{1}$ agonist, suggesting a partial agonist activity on the $B_{2}$ receptor. The injection of $B_{1}$ agonist in LPS-treated rats increased plasma extravasation in the urinary bladder (54\%), and main (29\%) and segmentar (48\%) bronchi. An increase in plasma extravasation was also observed in the duodenum (56\%), ileum (38\%) and trachea (37\%), similar to that observed in response to $B_{1}$ agonist, in non-LPS treated rats. In LPS-pretreated rats, the $B_{1}$ antagonist injected before the $B_{1}$ agonist significantly reduced the plasma extravasation in all tissues studied, with the exception of the urinary bladder. The $B_{2}$ antagonist did not prevent the plasma extravasation mediated by the $B_{1}$ agonist in LPS-pretreated rats.

\section{Discussion}

The results presented indicate that kinins are able to induce plasma extravasation in all the tissues of rats analyzed in this study, namely the duodenum, ileum, urinary bladder, trachea, and main bronchi and segmentar bronchi. The effects appear to be mediated by $B_{1}$ and/or $B_{2}$ receptors. $B_{1}$ receptor-mediated plasma extravasation responses were enhanced after LPS treatment in the duodenum, ileum, trachea, main and segmentar bronchi, in which the $B_{1}$ agonist (Sar[D-Phe ${ }^{8}$-des-Arg ${ }^{9}$-BK) induced a significant increase in the dye content, suggesting that this toxin promotes the formation of $B_{1}$ receptor in the rat, as it does in the rabbit and other animal species. ${ }^{1,12}$

It is generally accepted that, while the expression of $B_{2}$ receptors is constitutive, expression of $B_{1}$ receptors is induced by tissue injury/inflammation. ${ }^{11}$ In this study, the presence and the de novo expression of $B_{1}$ receptors following LPS treatment was found in main and segmentar bronchi, the duodenum and the ileum, and was demonstrated by the fact that the specific and selective $B_{1}$ antagonist ([Leu $\left.{ }^{8}\right]$ desArg $\left.{ }^{9}-\mathrm{BK}\right)$ completely prevented the combined effect of LPS and $B_{1}$ agonist. In addition, the $B_{2}$ antagonist was found to be inactive against $B_{1}$ agonist. In the urinary bladder, LPS alone induced a significant increase in plasma extravasation, but did not promote de novo expression of $\mathrm{B}_{1}$ receptors because the $\mathrm{B}_{1}$ antagonist had no effect against LPS treatment. Recently, studies have provided evidence for the expression of kinin $B_{1}$ receptors mediating bladder smooth muscle contraction after cyclophosphamideinduced inflammation in rats. ${ }^{8}$ Also, other authors showed evidence for the time-dependent induction of $B_{1}$ receptor expression in mice mediating the contraction of urinary bladder. ${ }^{13}$ However, our results suggest that the LPS-induced increase in plasma extravasation 


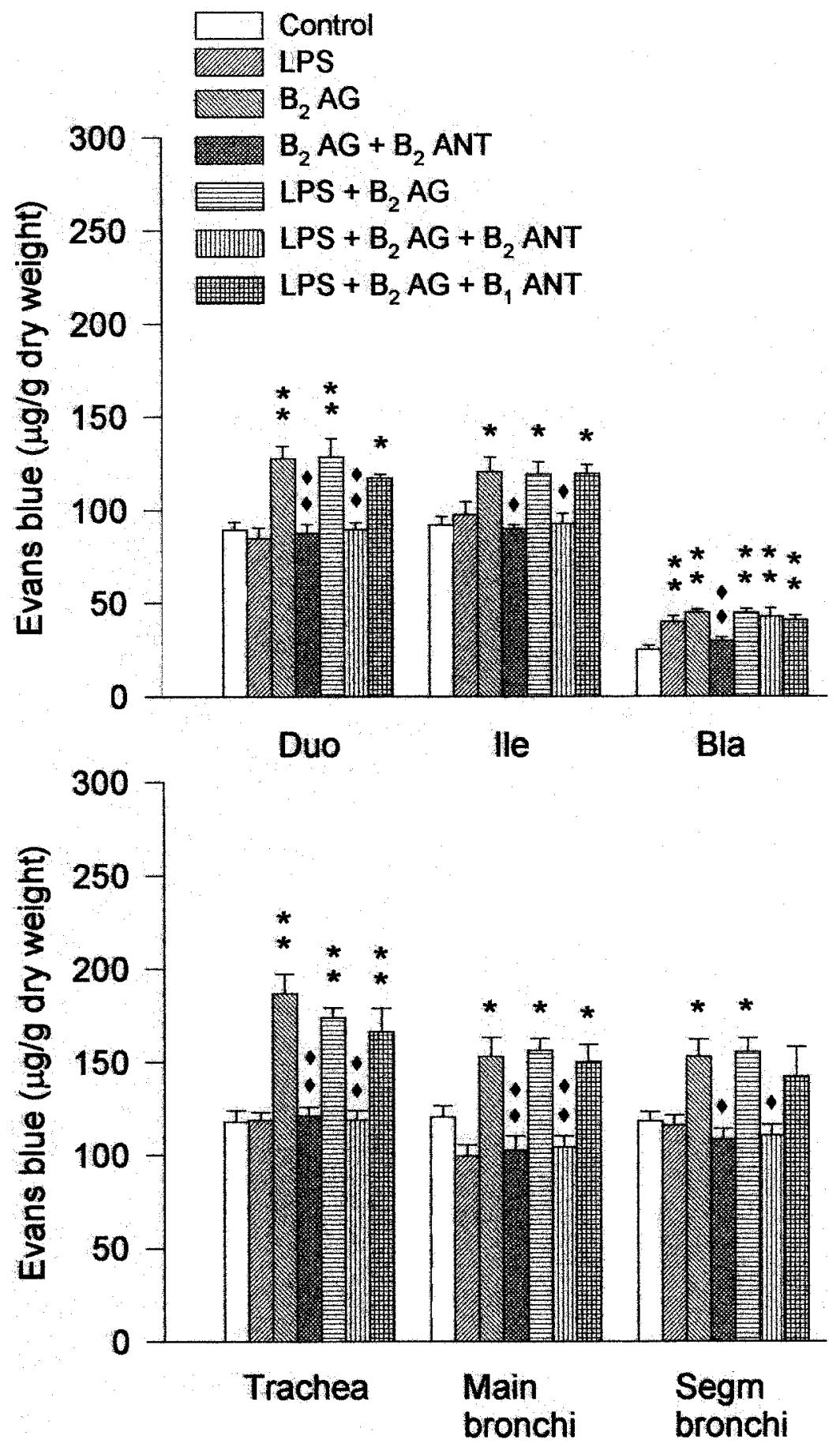

FIG. 1. Effects of kinin $B_{2}$ agonist, $B_{2}$ antagonist and lipopolysaccharide (LPS), alone and in combination, on plasma extravasation in various organs of the rat. Duo, Duodenum; lle, ileum; Bla, urinary bladder; Segm bronchi, segmentar bronchi. Columns indicate the means, and vertical bars the standard error of six rats. LPS, LPS-treated rats; $B_{2} A G, B_{2}$ agonist; $B_{2} A N T$, $\mathrm{B}_{2}$ antagonist; $\mathrm{B}_{1}$ ANT, $\mathrm{B}_{1}$ antagonist. ${ }^{*} p<0.05,{ }^{* *} p<0.01$, significance with respect to controls, and $\bullet p<0.05, \bullet p<0.01$ significance as compared with $B_{2}$ agonist and LPS $+B_{2}$ agonist.

observed in the urinary bladder is caused by mechanisms that may be independent of kinin receptor activation. This finding requires further investigation.

The $B_{1}$ receptor is known to be constitutively expressed in vivo both in the dog coronary system and in the cat pulmonary vascular bed. ${ }^{11}$ In this study, we used the same $B_{1}$ agonist (Sar[D-Phe ${ }^{8}$-des-Arg9'$\mathrm{BK}$ ) as that used previously ${ }^{8}$ because this drug is more resistant to enzymatic metabolism than the alternative $B_{1}$ agonist desArg-BK. ${ }^{6,9}$ Our results showed that $B_{1}$ receptor-mediated plasma extravasation occurred in the duodenum, ileum and trachea of normal rats. Moreover, the effect of this drug was not inhibited by 


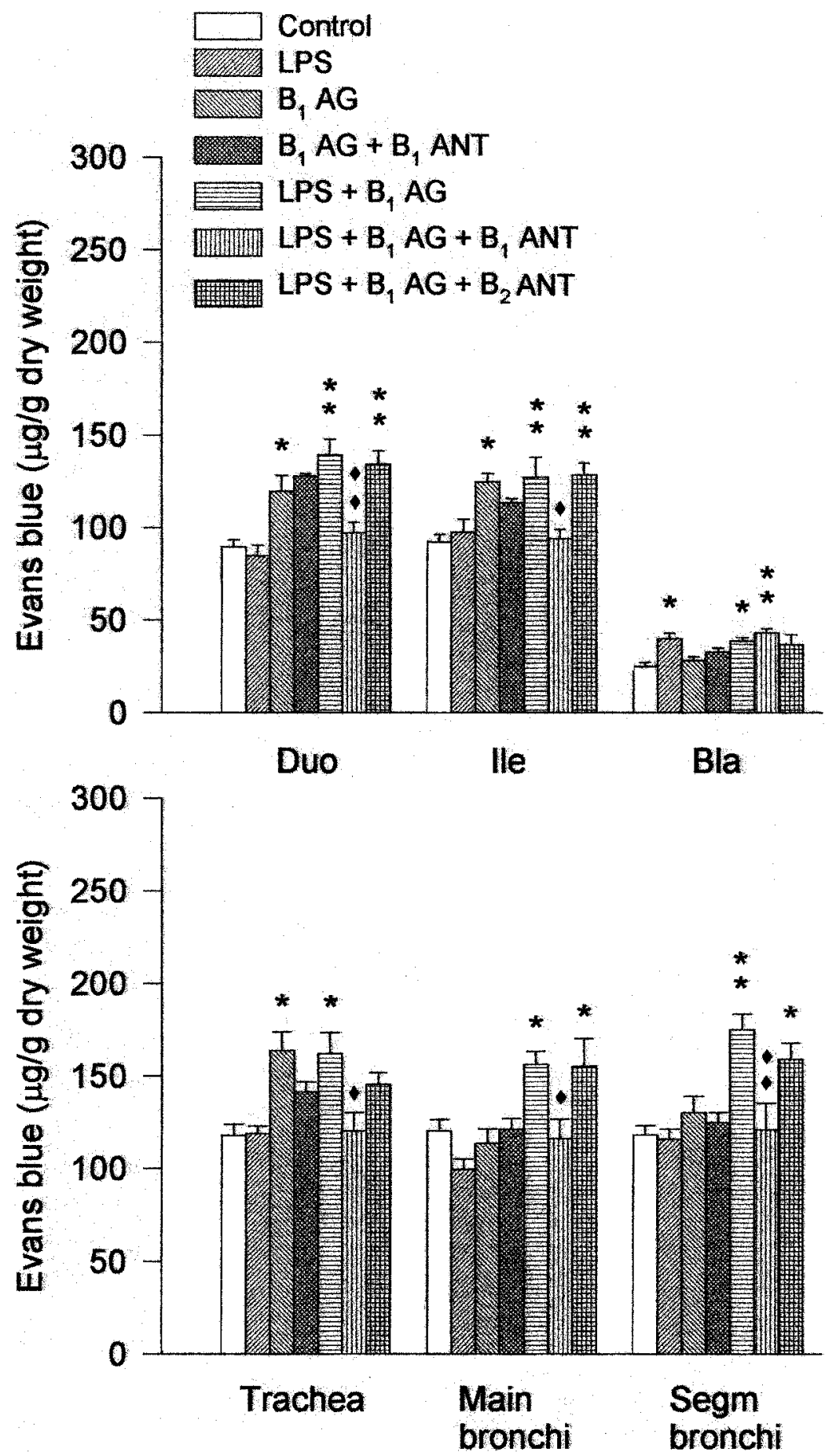

FIG. 2. Effects of kinin $B_{1}$ agonist, $B_{1}$ antagonists and lipopolysaccharide (LPS), alone and in combination, on plasma extravasation in various organs of the rat. Duo, Duodenum; lle, ileum; Bla, urinary bladder; Segm bronchi, segmentar bronchi. Columns indicate the means, and vertical bars the standard error of six rats. LPS, LPS-treated rats; $B_{1} A G, B_{1}$ agonist; $B_{1} A N T$, $\mathrm{B}_{1}$ antagonist; $\mathrm{B}_{2}$ ANT, $\mathrm{B}_{2}$ antagonist. ${ }^{*} p<0.05,{ }^{*} p<0.01$, significance with respect to controls, $p<0.05, \diamond p<0.01$ significance as compared with $B_{1}$ agonist and LPS $+B_{1}$ agonist.

treatment with the $B_{1}$ antagonist, suggesting a partial agonist activity of the $B_{1}$ agonist at the $B_{2}$ receptor. On the contrary, the treatment with LPS, which significantly increased the effect of the $B_{1}$ agonist in the duodenum, ileum, trachea, main and segmentar bronchi, was blocked by the $B_{1}$ antagonist but not by the $\mathrm{B}_{2}$ antagonist. Increased plasma extravasation has been attributed to $B_{2}$ receptors. ${ }^{6}$ Our results are consistent with other vascular responses mediated by $B_{1}$ receptors observed in LPS-pretreated rabbits ${ }^{14}$ and rats. ${ }^{4,5,15}$

Bradykinin increased plasma extravasation in all tissues analyzed in this report. This effect appears to be due to activation of $B_{2}$ receptors as it was not 
enhanced by the pretreatment of the animal with LPS and this effect was blocked by the $\mathrm{B}_{2}$ antagonist. This conclusion is further supported by the finding that the $B_{1}$ antagonist was found to be inactive against bradykinin-induced plasma extravasation.

It is therefore concluded that bradykinin and the enzyme-resistant $B_{1}$ agonist (Sar[D-Phe ${ }^{8}$ ]-des-Arg ${ }^{9}$-BK) promote plasma extravasation by acting on two receptor types, $B_{1}$ and $B_{2}$. Furthermore, we showed that $B_{2}$ receptors are present in rat duodenum, ileum, urinary bladder, trachea and main and segmentar bronchi, mediating plasma extravasation. Most importantly, we demonstrated that LPS is able to promote the de novo formation of kinin $\mathrm{B}_{1}$ receptors, which subsequently mediate plasma extravasation in these tissues.

ACKNOWLEDGEMENTS. The authors thank Dr Gareth Cuttle for correcting the English. This work was supported by CAPES (Brazil).

\section{References}

1. Bhoola KD, Figueroa CD, Worthy K. Bioregulation of kinins: kallikreins, kininogens and kininases. Pharmacol Rev 1992; 44: 1-80.

2. Regoli D, Barabé J. Pharmacology of bradykinin and related kinins. Pharmacol Rev 1980; 32: 1-46.

3. Hall JM. Bradykinin receptors: pharmacological properties and biological roles. Pharmacol Rev 1992; 56: 131-190.

4. Nicolau M, Feltrin MR, Regoli D. Induction of bradykinin $B_{1}$ hypotensive receptors in rats by lipopolysaccharide. Can J Physiol Pharmacol 1996; 74: 337-340.

5. McLean PG, Perretti M, Ahluwalia A. Inducible expression of the kinin $B_{1}$ receptor in the endotoxemic heart: mechanisms of des-Arg ${ }^{9}$-bradykinininduced coronary vasodilatation. Br J Pharmacol 1999; 128: 275-282.

6. Marceau $F$. Kinin $B_{1}$ receptors: a review. Immunopharmacology 1995 ; 30: $1-26$.

7. Wohlfart P, Dedio J, Wirth K, Scholkens BA, Wiemer G. Different $B_{1}$ kinin receptor expression and pharmacology in endothelial cells of different origins and species. J Pharmacol Exp Ther 1997; 280: 1109-1116.

8. Lecci A, Meini S, Tramontana M, Giuliani S, Criscuoli M, Maggi CA. Kinin $B_{1}$ receptor mediated motor responses in normal or inflamed rat urinary bladder in vivo. Regul Pept 1999; 80: 41-47.

9. Drapeau G, deBlois D, Marceau F. Hypotensive effects of Lys-des-Arg9bradykinin and metabolically protected agonists of $B_{1}$ receptors for kinins. J Pharmacol Exp Ther 1991; 259: 997-1003.

10. Nicolau M, Sirois MG, Bui M, Plante GE, Sirois P, Regoli D. Plasma extravasation induced by neurokinins in conscious rats: receptor characterization with agonists and antagonists. Can J Physiol Pharmacol 1993; 71: 217-221.

11. Marceau $F$, Hess JF, Bachvarov DR. The $B_{1}$ receptors for kinins. Pharmacol Rev 1998; 50: 357-386.

12. Belichard P, Luccarini JM, Defrene E, Faye P, Franck RM, Duclos H, Paquet $J L$, Pruneau D. Pharmacological and molecular evidence for kinin $B_{1}$ receptor expression in urinary bladder of cyclophosphamide-treated rats. Br J Pharmacol 1999; 128:213-219.

13. Trevisani M, Schmidlin F, Tognetto M, Nijkamp FP, Gies JP, Frossard N, Amadesi S, Folkerts G, Geppetti P. Evidence for in vitro expression of $\mathrm{B}_{1}$ receptor in the mouse trachea and urinary bladder. Br J Pharmacol 1999; 126: 1293-1300.

14. Audet R, Rioux F, Drapeau G, Marceau F. Cardiovascular effects of Sar[D Phe $^{8}$ ]-des-Arg-bradykinin, a metabolically protected agonist of $\mathrm{B}_{1}$ receptor for kinins, in the anesthetized rabbit pretreated with a sublethal dose of bacterial lipopolysaccharide. J Pharmacol Exp Ther 1997; 280: $6-15$.

15. Cruwys SC, Garrett NE, Perkins MN, Blake DR, Kidd BL. The role of bradykinin $B_{1}$ receptors in the maintenance of intra-articular plasma extravasation in chronic antigen-induced arthritis. Br J Pharmacol 1994; 113: $940-944$ 


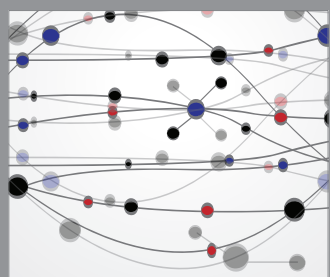

The Scientific World Journal
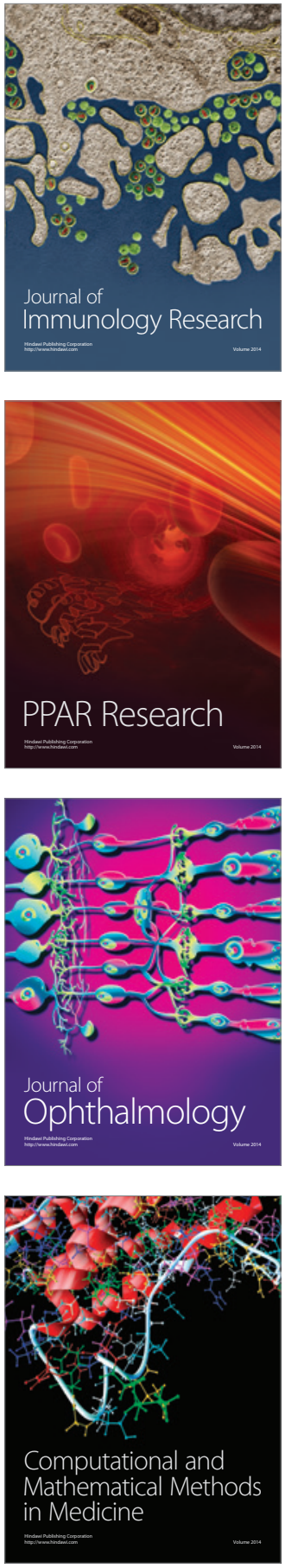

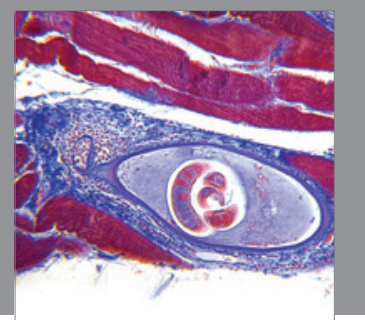

Gastroenterology

Research and Practice
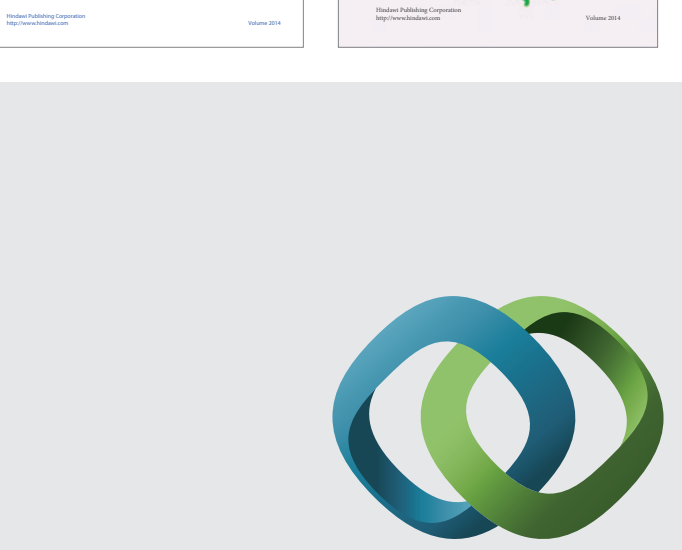

\section{Hindawi}

Submit your manuscripts at

http://www.hindawi.com
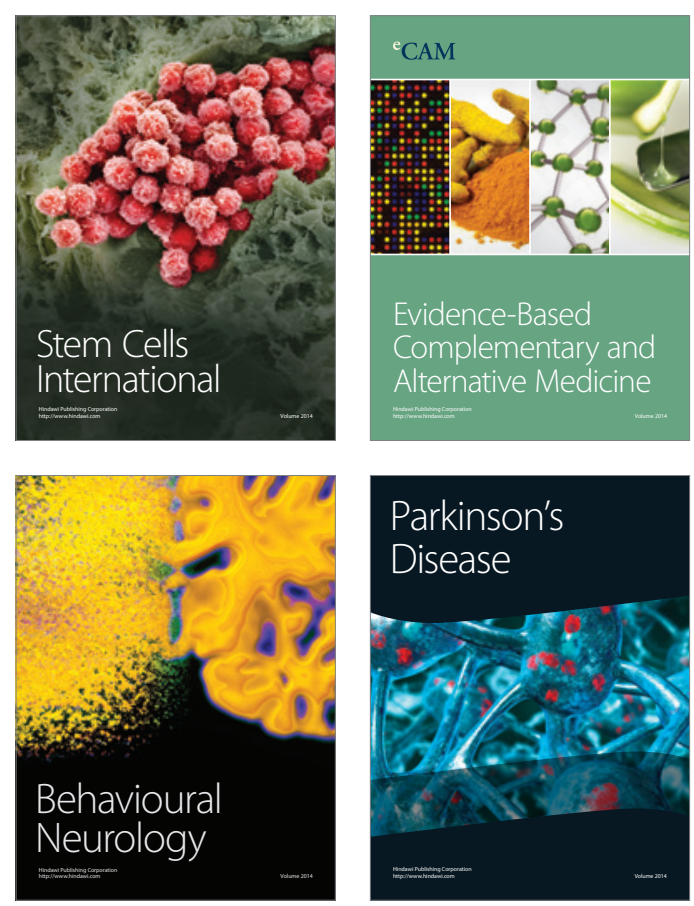

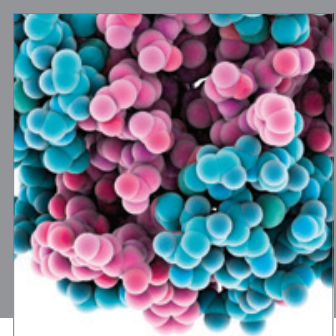

Journal of
Diabetes Research

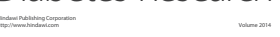

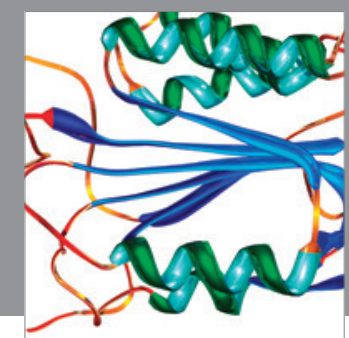

Disease Markers
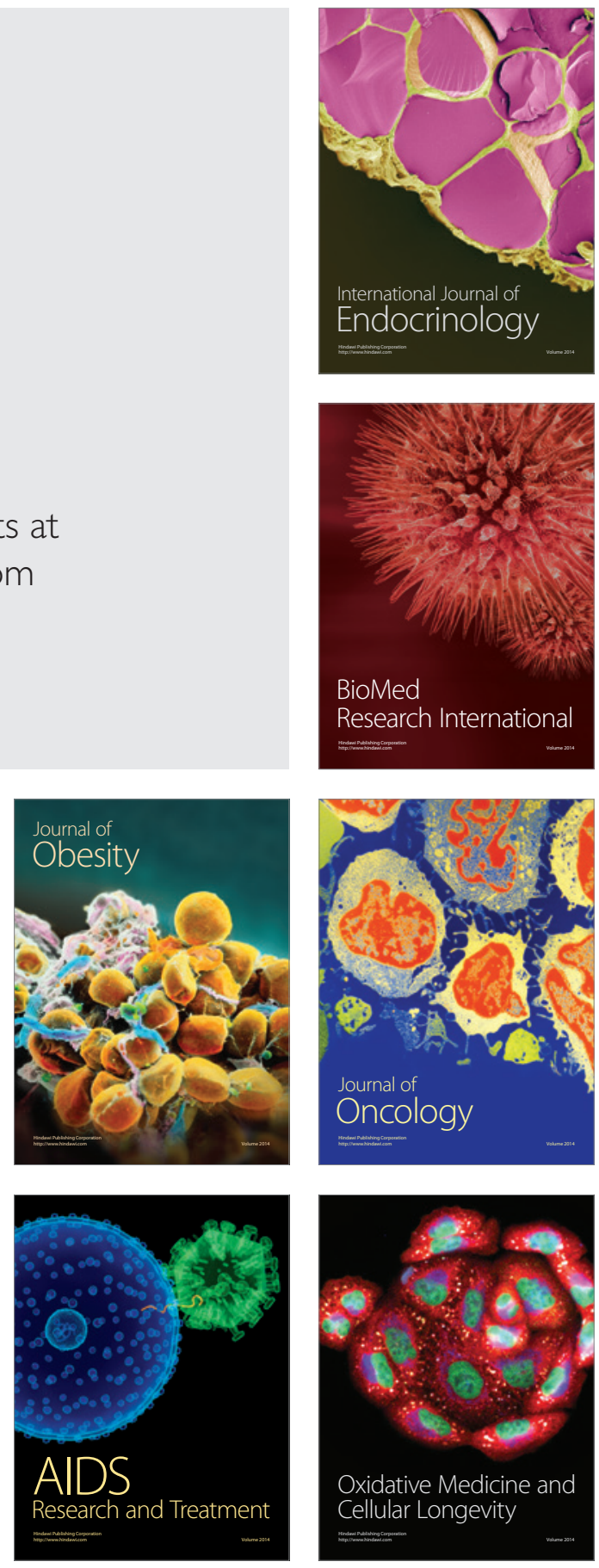